\title{
Three Weekly Versus Weekly Cisplatin as Radiosensitizer in Head and Neck Cancer: a Decision Dilemma
}

\author{
Preety Negi $^{1 *}$, Pamela Alice Kingsley ${ }^{2}$, Himanshu Srivastava $^{3}$, Surender Kumar \\ Sharma ${ }^{4}$
}

\begin{abstract}
Cisplatin-based concurrent chemoradiation plays an undisputed key role as definitive treatment in unresectable patients with locally advanced squamous cell carcinoma head and neck or as an organ preservation strategy. Treatment with $100 \mathrm{mg} / \mathrm{m} 2$ 3-weekly cisplatin is considered the standard of care but is often associated with several adverse events. The optimum drug schedule of administration remains to be defined and presently, there is insufficient data limiting conclusions about the relative tolerability of one regimen over the other. This review addresses regarding the optimal dose schedule of cisplatin focusing mainly on three-weekly and weekly dose of cisplatin based concurrent chemoradiotherapy in locally advanced head and neck cancer with an emphasis on mucositis, dermatitis, systemic toxicity, compliance, and treatment interruptions. To derive a definitive conclusion, large prospective randomized trials are needed directly comparing standard 3-weekly cisplatin $\left(100 \mathrm{mg} / \mathrm{m}^{2}\right) \mathrm{with}$ weekly schedule $\left(30-40 \mathrm{mg} / \mathrm{m}^{2}\right)$ of concurrent cisplatin based chemoradiotherapy in locally advanced squamous cell carcinoma head and neck.
\end{abstract}

Keywords: Head and neck cancer - cisplatin - radiosensitization - treatment schedule decisions

Asian Pac J Cancer Prev, 17 (4), 1617-1623

\section{Introduction}

Head and neck cancer is the sixth most common cancer worldwide with an estimated annual burden of $6,33,000$ incident cases and 3, 55,000 deaths (Jemal et al., 2011). Overall $57.5 \%$ of the total head and neck cancers occur in Asia, accounting for approximately $30 \%$ of all cancers in India (Kulkarni et al., 2013). In developing countries approximately $80 \%$ of cases present with locally advanced head and neck cancer (LA-HNC) (Mohanty et al., 2000). The treatment of these patients has evolved since the introduction of combined modality treatment (Sambargi et al., 2012).

For patients with locally advanced disease not amenable to surgical resection, concurrent chemoradiotherapy (CCRT) is now recognized worldwide as a standard treatment option (Adelstein et al., 2003). Most of the randomized controlled trials have accepted cisplatin in a dose of $100 \mathrm{mg} / \mathrm{m}^{2}$ given every 3-weeks concurrent with RT as a standard reference regimen in the definitive and adjuvant setting (Adelstein et al., 2003; Bernier et al., 2004; Cooper et al., 2004). Despite this, still uncertainties exist regarding appropriate chemoradiotherapy (CRT) regimens because of significant heterogeneity in published data with respect to patient selection, chemotherapy (CT) schedules and RT fractionation (Browman et al.,
2001; Hao et al., 2006). In addition, the use of 3-weekly schedule has been an area of concern for the clinicians as well as for the patients in view of challenges imposed by this schedule such as acute toxicities, treatment compliance and hospitalization for supportive care. Moreover, suboptimal compliance with this schedule could jeopardize the treatment outcome, resulting in poorer loco-regional control and shorter survival (Pajak et al., 1991; Browman et al., 2001; Adelstein et al., 2003). In an effort to overcome these challenges, splitting the 3 -weekly cisplatin into a weekly cisplatin schedule with dosage ranging from 20 to $40 \mathrm{mg} / \mathrm{m}^{2}$ has been investigated with some promising results achieving better antitumor efficacy, fewer side effects, and lower cost and hospitalization rates. Considering the controversial nature of the available research regarding the optimal scheduling of cisplatin - based concurrent chemoradiotherapy in LA$\mathrm{HNC}$, we undertook this comprehensive review to focus on the question regarding the use of standard 3-weekly cisplatin $\left(100 \mathrm{mg} / \mathrm{m}^{2}\right)$ in comparison to the more popular weekly cisplatin (20 to $40 \mathrm{mg} / \mathrm{m}^{2}$ ) concurrent with radiation therapy.

After thoroughly searching the published medical literature using internet and PubMed we found that the experience with "Comparison between three-weekly versus weekly schedule of cisplatin based concurrent

${ }^{1}$ Radiation Oncology, Assistant Professor, ${ }^{2}$ Radiation Oncology, Professor, Christian Medical College \& Hospital, Ludhiana , Ludhiana, ${ }^{3}$ Radiation Oncology, Attending Consultant, ${ }^{4}$ Radiation Oncology, Senior Consultant, Rajiv Gandhi Cancer Institute \& Research Centre,New Delhi, India*For correspondence: drpreetinegi@gmail.com 
chemoradiotherapy in head and neck cancer" is mainly limited to less than 10 original articles mainly retrospective institutional reports. We could not find any review article on this debatable topic.

\section{Historical Background}

The success story of cisplatin began when Dr. Barnett Rosenberg and his colleagues (Rosenberg et al., 1965) found that certain electrolysis products of platinum mesh electrodes were capable of inhibiting cell division dramatically in Escherichia coli creating lot of interest in the possible use of these products in the treatment of cancer. This led to the accidental identification of cisdichloro-diammine-platinum (cisplatin; CDDP) as the agent responsible for this activity. Since then it opened a new era for the use of platinum compounds in the treatment of various solid malignant tumours, especially squamous cell cancers of the head and neck region, in both pediatric and adult age groups (Goncalves et al., 2013) also including testicular, ovarian, bladder, esophageal, small and non-small cell lung, breast, cervical, stomach and prostate cancers, as well as Hodgkin's and non-Hodgkin's lymphomas, neuroblastoma, sarcomas, multiple myeloma, melanoma, and mesothelioma (Florea et al., 2011).

\section{Cisplatin as Radiosensitizer}

Over the last several years cisplatin has received the maximum attention as radiosensitizer in head and neck cancer. Cisplatin is a platinum compound with complex mechanism of action when it comes to radiation-drug interactions thereby leading to increased cell damage and cell kill. Cisplatin demonstrates radiosensitizing properties through inhibition of DNA repair and cell cycle arrest (Lawrence et al., 2003). Furthermore, it exhibits radiosensitization of hypoxic cells due to scavenging of hydrated electrons by the platinum complex and formation of local concentrations of $\mathrm{OH}$ radicals, which eventually damage the DNA. Cisplatin was shown to have cytostatic properties by blocking the cells in the G2 phase of the mitotic cycle. Moreover, ionizing radiation can also increase cellular uptake of platinum (Yang et al., 1995). To date, the most important property of cisplatin as confirmed by preclinical and clinical studies is the ability to form DNA adducts. Cisplatin can form both intrastrand and interstrand adducts with the DNA; thereby distorting the DNA structure and blocking nucleotide replication and transcription (Bagri et al., 2014).

\section{Combined Modality Treatment for Locally Advanced Head and Neck Carcinoma}

Concurrent chemoradiation has been widely adopted as standard of care for LA-HNC after the publication of a large and most comprehensive meta-analysis based on individual patient data of 10,741 patients in 63 randomized trials (Pignon et al., 2000). The meta-analysis was updated and extended to include 16,640 patients treated in 87 trials (Pignon et al., 2007) confirming that concurrent chemoradiation conferred an absolute survival benefit of $8 \%$ at 2 and 5 years. Regarding the type of drugs to be combined concomitantly with radiotherapy (RT), cisplatin alone, platinum with 5-Fluorouracil (5-FU) or other poly-chemotherapy including either platin or 5-FU gave a benefit of the same magnitude. In contrast, monochemotherapy with a drug other than cisplatin led to inferior results and is not recommended in routine practice (Pignon et al., 2009).

The choice of particular regimen given at various institutions varies markedly from every 3 weeks $(100 \mathrm{mg} /$ $\left.\mathrm{m}^{2}\right)$ to low-dose daily $\left(6 \mathrm{mg} / \mathrm{m}^{2)}\right.$ administration. Among the weekly schedule, doses as low as $20 \mathrm{mg} / \mathrm{m}^{2}$ concurrent with RT have been tried. An Intergroup randomized trial (Quon et al., 2011) of 307 eligible patients comparing $20 \mathrm{mg} / \mathrm{m}^{2}$ of cisplatin with RT to the same RT alone demonstrated no improvement in overall survival (OS) or freedom from failure, suggesting that $20 \mathrm{mg} / \mathrm{m}^{2}$ (weekly) was too low a dose. Unfortunately, the study also revealed increased risk of late laryngeal and esophageal toxicities. In the face of recognized toxicity, institutional practices favouring a weekly schedule have typically favoured doses of $\geq 30 \mathrm{mg} / \mathrm{m}^{2}$. Asif et al. subjected 30 patients to Inj. Cisplatin at an intermediate dose of $30 \mathrm{mg} / \mathrm{m}^{2}$ intravenously once a week with RT compared to RT alone group (Asif et al., 2003). None of the patients in the weekly CRT group developed systemic toxicity and only $13.3 \%$ patients developed grade III mucositis. The same regimen has been employed with altered fractionation RT either hyperfractionation or concomitant boost technique and was found to be safe and effective (Newlin et al., 2010). Maqbool et al. (2012) prospectively investigated the feasibility and acute toxicity patterns of $40 \mathrm{mg} / \mathrm{m}^{2}$ weekly cisplatin with conventionally fractionated external beam radiotherapy (EBRT) in head and neck squamous cell carcinoma (HNSCC) patients (Maqbool et al., 2012). The authors concluded that use of weekly cisplatin as an outpatient treatment is an attractive schedule from the standpoint of delivery, tolerance, compliance and costeffectiveness.

\section{Acute Toxicity (Mucositis, Dermatitis)}

Mucositis is the commonest dose-limiting nonhematological toxicity associated with cisplatin use whether 3-weekly or weekly schedule. Maqbool et al. reported mucositis to be the predominant toxicity requiring interruptions in radiation therapy and chemotherapy dose modifications (Maqbool et al., 2012). In a study by Tsan et al. the patients receiving low dose weekly cisplatin $\left(40 \mathrm{mg} / \mathrm{m}^{2}\right)$ suffered more severe ( $\geq$ grade 3 ) mucositis than patients receiving 3 -weekly cisplatin $\left(100 \mathrm{mg} / \mathrm{m}^{2}\right)$ (75\% vs. 38.5\%; $\mathrm{p}=0.012$ ). The main reasons for this observation of some difference in toxicity could have been forced hydration and post-CT care of patients which was mandatory only for 3-weekly arm as suggested by the authors (Tsan et al., 2012). Similar findings were seen in a retrospective analysis of 55 patients by Kose et al. demonstrating a higher incidence of grade III - IV mucositis with the weekly regimen (Kose et al., 2011). They reported that patients with grade III - IV mucositis during CRT had significantly higher median OS than those 
Three Weekly Versus Weekly Cisplatin as Radiosensitizer in Head and Neck Cancer: a Decision Dilemma

with grade I - II mucositis. An unusually low incidence $(29 \%)$ of grade III or worse mucositis has also been demonstrated with the weekly regimen mostly in patients receiving more intense treatment i.e. doses $\geq 66 \mathrm{~Gy}$ and 6 or more cycles of chemotherapy (Gupta et al., 2009). Different results have on the contrary been published (Geeta et al., 2006; Mitra et al., 2011) showing a trend to decreased toxicity with 3-weekly cisplatin than weekly cisplatin, as their weekly cisplatin schedule resulted in a higher rate of severe mucositis, significant in both univariate and multivariate analysis. In a retrospective analysis comparing the two regimens of concurrent chemotherapy with intensity-modulated radiotherapy, no statistically significant difference in the incidence of grade III - IV mucositis was found (32.5\% for weekly group $v s$. $16.6 \%$ for 3-weekly group; $\mathrm{p}=0.08$ ) (Espeli et al., 2012).

Radiation dermatitis is experienced to various degrees by the majority of patients undergoing RT for LA-HNC (Wendt et al., 1998; Calais et al., 1999; Bourhis et al., 2006). In most patients, the radiation dermatitis is mild to moderate (grades 1 and 2), but according to Bonner et al. $\sim 20 \%-25 \%$ of patients experience severe reactions on receiving combination of Cetuximab and RT (Bonner et al., 2006). Espeli et al. reported higher incidence of grade II - III skin toxicity for 3-weekly group as compared to weekly group ( $\mathrm{p}=0.5)$ (Espeli et al., 2012). Similarly, Ho et al. found that patients treated with 3-weekly cisplatin seemed to suffer more grade 3 radiation dermatitis (56\% vs. 26\%), although not statistically significant (Ho et al., 2008).

\section{Systemic Toxicities (Hematological, Auditory, Renal Impairment)}

Most published reports have described the incidence of Grade 3 / 4 neutropenia as approximately 30\% with 3-weekly cisplatin compared with $10-15 \%$ with weekly cisplatin concurrent with RT, thus highlighting the importance of delivery of fractionated doses of chemotherapy (Cooper et al., 2004; Zenda et al., 2009; Homma et al., 2011; Mitra et al., 2011; Kiyota et al., 2012; Osman et al., 2014). Contradictory to this, various studies have reported no difference in terms of hematological toxicities between the two comparative arms (Kose et al., 2011; Tsan et al., 2012).

Auditory impairment after cisplatin therapy has been reported to be dose dependent, schedule dependent, and frequency dependent (Rademaker-Lakhai et al., 2006). De Jongh et al. described the toxicity of weekly high-dose cisplatin ( 70 to $85 \mathrm{mg} / \mathrm{m}^{2}$ ) in 400 patients with advanced solid tumours treated in the period 1990-2001 who took part in phase I / II trials (De Jongh et al., 2003). They observed ototoxicity in $2.5 \%$ of the patients. In the RTOG 95-01 study, the incidence of Grade 3 or more auditory disorders was $10 \%$ after 3-weekly cisplatin concurrent with RT (Cooper et al., 2004). However, we could not find any reports on Grade 3 or more auditory disorders with the weekly cisplatin schedule.

Although rare, there have been reports of renal disorders with concurrent cisplatin-based CRT. It is suggested that as the 3rd - 4th week of treatment is reached, oral mucosal reactions increase affecting oral intake further adding to the cisplatin-induced nephrotoxicity (Bagri et al., 2014). In a retrospective overseas study reported by Uygun et al. the incidence of Grade 3 / 4 renal disorders was lower with weekly cisplatin than with 3-weekly cisplatin (Uygun et al., 2009). A Japanese study reported that, although no difference was observed in the incidence of Grade 3 / 4 renal toxicity, the incidence of Grade 2 or more, for which dose reduction or discontinuation of cisplatin must be considered, was $30-32 \%$ in 3-weekly cisplatin compared with $2-15 \%$ in weekly cisplatin concurrent

Table 1. Published Series of Concurrent Cisplatin Schedules Compiling Patients Receiving 3-Weekly Versus Weekly Cisplatin Regimes for Locally Advanced Squamous Cell Carcinoma Head and Neck

\begin{tabular}{|c|c|c|c|c|c|c|c|c|c|c|}
\hline S.No. & $\begin{array}{c}\text { Name \& } \\
\text { Year of } \\
\text { Publication }\end{array}$ & $\begin{array}{l}\text { No. of } \\
\text { Patients }\end{array}$ & $\begin{array}{c}\mathrm{RP} / \\
\mathrm{PP}\end{array}$ & $\begin{array}{c}\text { Definitive / } \\
\text { Adjuvant }\end{array}$ & $\begin{array}{c}\text { 3-weekly } \\
\text { vs weekly } \\
\text { CDDP dose } \\
(\mathrm{mg} / \mathrm{m} 2)\end{array}$ & Mucositis & Neutropenia & Response & Compliance & $\begin{array}{c}\text { Survival (OS) } \\
3 \mathrm{w} \text { vs w }\end{array}$ \\
\hline 1 & $\begin{array}{c}\text { Geeta et al, } \\
2006\end{array}$ & 83 & $\mathrm{RP}$ & Definitive & 100 vs 40 & $\begin{array}{c}\uparrow \text { in } \\
\text { weekly }\end{array}$ & $\uparrow$ in weekly & $\mathrm{NE}$ & $\uparrow$ in 3 weekly & NE \\
\hline 2 & $\begin{array}{c}\text { Ho et al, } \\
2008\end{array}$ & 51 & $\mathrm{RP}$ & Definitive & $\begin{array}{c}80-100 \text { vs } \\
33-40\end{array}$ & NE & Similar & Similar & $\uparrow$ in weekly & $\mathrm{NE}$ \\
\hline 3 & $\begin{array}{l}\text { Uygun et } \\
\text { al, } 2009\end{array}$ & 50 & $\mathrm{PP}$ & Definitive & 100 vs 40 & $\begin{array}{c}\uparrow \text { in } 3 \\
\text { weekly }\end{array}$ & $\begin{array}{c}\uparrow \text { in } 3 \\
\text { weekly }\end{array}$ & Similar & NE & $\mathrm{NE}$ \\
\hline 4 & $\begin{array}{c}\text { Mitra et al, } \\
2011\end{array}$ & 90 & PP & Definitive & 100 vs 30 & Similar & $\begin{array}{c}\uparrow \text { in } 3 \\
\text { weekly }\end{array}$ & $\square$ in 3 weekly & Similar & $\mathrm{NE}$ \\
\hline 5 & $\begin{array}{l}\text { Kose et al, } \\
\quad 2011\end{array}$ & 55 & $\mathrm{RP}$ & Definitive & 100 vs 30 & $\begin{array}{c}\uparrow \text { in } \\
\text { weekly }\end{array}$ & $\begin{array}{c}\uparrow \text { in } 3 \\
\text { weekly }\end{array}$ & NE & $\mathrm{NE}$ & $\begin{array}{l}\text { Almost } \\
\text { Similar }\end{array}$ \\
\hline 6 & $\begin{array}{c}\text { Tsan et al, } \\
2012\end{array}$ & 55 & PP & Adjuvant & 100 vs 40 & $\begin{array}{c}\uparrow \text { in } \\
\text { weekly }\end{array}$ & Similar & $\mathrm{NE}$ & $\uparrow$ in 3 weekly & $\mathrm{NE}$ \\
\hline 7 & $\begin{array}{c}\text { Espeli et al, } \\
2012\end{array}$ & 94 & $\mathrm{RP}$ & Both & 100 vs 40 & $\begin{array}{c}\uparrow \text { in } \\
\text { weekly }\end{array}$ & NE & $\mathrm{NE}$ & $\mathrm{NE}$ & $44 \%$ vs $42 \%$ \\
\hline 8 & $\begin{array}{c}\text { Geiger et } \\
\text { al, } 2014\end{array}$ & 104 & $\mathrm{RP}$ & Adjuvant & $\begin{array}{l}100 \text { vs } 30 \\
-40\end{array}$ & $\mathrm{NE}$ & $\mathrm{NE}$ & $\mathrm{NE}$ & $\mathrm{NE}$ & $91 \%$ vs $86 \%$ \\
\hline 9 & $\begin{array}{c}\text { Fayette et } \\
\text { al, } 2015\end{array}$ & 266 & $\mathrm{RP}$ & Adjuvant & 100 vs 40 & $\begin{array}{c}\uparrow \text { in } 3 \\
\text { weekly }\end{array}$ & $\begin{array}{c}\uparrow \text { in } 3 \\
\text { weekly }\end{array}$ & $\mathrm{NE}$ & $\mathrm{NE}$ & $\begin{array}{c}62.3 \% \text { vs } \\
52.6 \%\end{array}$ \\
\hline
\end{tabular}

$\mathrm{RP}=$ Retrospective, $\mathrm{PP}=$ Prospective, $\mathrm{NE}=$ not evaluated,$\uparrow=$ Higher, $\mathrm{OS}=$ Overall survival, $3 \mathrm{w}=3 \mathrm{weekly}, \mathrm{w}=\mathrm{weekly}$ 
with RT, showing a significantly lower incidence with the weekly schedule (Kiyota et al., 2012). In a phase III randomized study on post-operative patients of carcinoma oral cavity, no difference in $\geq$ grade 3 renal toxicity was observed among the patients receiving low dose weekly cisplatin $\left(40 \mathrm{mg} / \mathrm{m}^{2}\right)$ and the patients receiving 3-weekly cisplatin $\left(100 \mathrm{mg} / \mathrm{m}^{2}\right)$ (Tsan et al., 2012). In a retrospective analysis of treatment outcome and nephrotoxicity of RT concurrent with either 3-weekly or weekly cisplatin in 94 patients with stage III / IV HNC (Espeli et al, 2012), the difference in the incidence of acute renal failure did not reach statistical significance (35\% for weekly group vs. $53.7 \%$ for 3 -weekly group; $\mathrm{p}=0.07)$. The frequency of chronic renal failure was significantly higher in 3-weekly group (12.5\% for weekly group vs. $29.6 \%$ for 3 -weekly group; $\mathrm{p}=0.04$ ). Although no patients developed irreversible renal failure requiring dialysis.

\section{Overall Survival and Response Rates}

Concerns about the survival benefit of either schedule should be balanced against the incidence of grade 3 or 4 drug toxicities. However, very few comparative studies have commented on this important end point of survival. Weekly cisplatin $(40 \mathrm{mg} / \mathrm{m} 2)$ with concurrent RT reported an impressive 2-year OS and local progression-free rates (PFR) of $93.7 \%$ and $88.0 \%$, respectively with complete response in the primary site in $98.1 \%$ patients (Homma et al., 2011). A large single institutional retrospective audit from India included 264 patients of LA-HNC treated with weekly cisplatin $30 \mathrm{mg} / \mathrm{m}^{2}$ concurrent with conventional RT. The estimated 5-years loco-regional control (LRC) and disease-free survival (DFS) were $46 \%$ and $43 \%$ respectively, while the OS was not computed (Gupta et al., 2009). Inferior 2-year local relapse-free, regional relapse-free, locoregional relapse-free, DFS, and OS rates of $48.8 \%, 57.8 \%, 33.2 \%$ and $49.7 \%$, respectively were reported by Krstevska et al. in 65 patients of oropharyngeal carcinoma treated with weekly cisplatin at $30 \mathrm{mg} / \mathrm{m} 2$ concurrent with 3-dimensional conformal RT (3D-CRT) (Krstevska et al., 2012). Kang et al. reported median OS of 42.7 months and 3-year DFS rate of $72.8 \%$ in stage IV HNSCC patients treated with low dose weekly cisplatin (20 to $30 \mathrm{mg} / \mathrm{m}^{2}$ ) concurrent with RT (Kang et al., 2015).

In a retrospective review by Geiger et al. on 104 patients with Stage III /IV HNSCC who had surgery followed by adjuvant chemoradiation therapy determining whether weekly cisplatin could be a safe and effective alternative as compared to standard 3-weekly chemotherapy. The authors concluded that there was no significant survival difference with high-dose or weekly cisplatin and weekly cisplatin in the adjuvant setting may be a better treatment for patients with HPV-positive oropharynx cancer to preserve survival and minimize toxicity (Geiger et al., 2014). In a report of 50 patients which included majority of patients with advanced laryngeal cancer, compared administration of bolus cisplatin at $100 \mathrm{mg} / \mathrm{m}^{2}$ every 3 weeks in younger patients with more favourable performance status (PS) to a schedule of weekly cisplatin at $40 \mathrm{mg} / \mathrm{m}^{2}$ given to older patients with less favourable PS, combined with conventionally fractionated RT to 70
Gy. At short-term follow-up, loco-regional disease control rates were comparable, but the follow-up was too short to make any firm conclusions (Uygun et al., 2009). In addition, no significant difference in the efficacy of the regimens (similar response rates and loco-regional control) was demonstrated by a randomized study comparing daily $\left(6 \mathrm{mg} / \mathrm{m}^{2}\right)$, weekly $\left(40 \mathrm{mg} / \mathrm{m}^{2}\right)$, and three-weekly $(100 \mathrm{mg} / \mathrm{m} 2)$ schedule of cisplatin with conventionally fractionated RT (Gladkov et al., 2007). The retrospective study of Espeli et al. suggested that 3-weekly schedule can be combined to IMRT atleast in the fit subset of patients. Moreover, patients treated with the standard 3-weekly regimen had a longer OS but this has been related to the selection of a fit and younger population rather than to a better antitumour activity; indeed, progression-free survival rates were not statistically different (Espeli et al., 2012).

\section{Compliance}

Achieving a good compliance with any form of treatment is necessary in order to minimize the interruption to the oncological treatment. With concurrent cisplatinbased CRT, compliance is a clinical challenge affecting 5-year local control, LRC and DFS. One of the largest single-centre experiences with 264 patients by Gupta et al. found that patients receiving $>85 \%$ of the planned dose ( 6 or more cycles of weekly CT) had a significantly superior 5-year local control (64.5\% vs $41.8 \%, \mathrm{p}=0.022)$; LRC ( $54.5 \%$ vs $26.8 \%, \mathrm{p}=0.009)$; and DFS (49.6\% vs $25.8 \%, \mathrm{p}=0.011)$ as compared to lesser dose intensity cisplatin ( 1 - 5 cycles of CT) concurrent with RT (Gupta et al., 2009). In the RTOG 9501 study, $61 \%$ of patients received all 3 planned cycles of cisplatin, $23 \%$ received 2 cycles, $13 \%$ received 1 cycle, and $2 \%$ received no chemotherapy (Cooper et al., 2004). In the EORTC 22931 study, compliance to chemotherapy decreased according to the courses delivered, as the first, second, and third cycles were administered to $88 \%, 66 \%$, and $49 \%$ of patients, respectively (Bernier et al., 2004). A retrospective review conducted by Bahl and co-workers. on 75 patients with carcinoma nasopharynx reported that only $43 \%$ patients received all three cycles of concurrent $\mathrm{CT}$ and $33.3 \%$ patients received the intended dose without a cumulative delay of atleast 7 days through the three cycles respectively (Bahl et al., 2004).

In an Indian trial 83 patients were randomized to receive either 3-weekly cisplatin $100 \mathrm{mg} / \mathrm{m} 2$ (group A) for 3 cycles or weekly cisplatin $40 \mathrm{mg} / \mathrm{m}^{2}$ (group B) for 6 cycles concurrent with RT. Treatment compliance was similar at $64 \%$ and $66 \%$ in groups A and B respectively (Geeta et al., 2006). Number of studies (Huguenin et al., 2004; Wee et al., 2005) showed that a substantial fraction of patients could not receive the third planned dose of cisplatin and suggested that a cumulative dose of 200 $\mathrm{mg} / \mathrm{m}^{2}$ might be adequate to yield same beneficial effect. However, weekly cisplatin dose ranging from $30-35 \mathrm{mg}$ / $\mathrm{m}^{2}$ had shown CT completion rate (7 cycles) to be from $64 \%$ to as high as $87 \%$ in the literature (Glaser et al., 1993; Mitra et al., 2011). It is worth noting that weekly cisplatin 
Three Weekly Versus Weekly Cisplatin as Radiosensitizer in Head and Neck Cancer: a Decision Dilemma

schedule is easier to manage than three-weekly cisplatin because of the regular monitoring of patients for toxicity allowing the schedule to be altered if required (Homma et al., 2011). Al-Sarraf et al. (2007) found that weekly cisplatin regimens have been mainly used for elderly unfit patients, while 3 -weekly $100 \mathrm{mg} / \mathrm{m}^{2}$ cisplatin has been considered the standard systemic treatment in CRT programs (Al-Sarraf et al., 2007).

\section{Treatment Interruption}

Finally, another concern that has been discussed is the treatment interruptions during RT as it affects the local control of the disease. In the first comparative study in 2006, 51 patients received cisplatin $\left(100 \mathrm{mg} / \mathrm{m}^{2}\right.$ every 3 -weekly), while 32 patients received cisplatin $\left(40 \mathrm{mg} / \mathrm{m}^{2}\right.$ weekly) during definitive RT. Contrary to expectations, the incidence of treatment interruptions was significantly higher $(41 \%$ vs $22 \%$; $\mathrm{p}=0.005)$ in the weekly cisplatin arm (Geeta et al., 2006). Frequent omission of weekly cisplatin $\left(40 \mathrm{mg} / \mathrm{m}^{2}\right)$ due to haematological toxicity has also been reported by Pala et al. (2012). Similar to this, Mitra et al. found more number of treatment interruptions in weekly CT group, which might be explained by higher percentage of patients with significant weight loss in the weekly group. These studies prompted the authors to suggest CT dose reduction and the need for prophylactic feeding tube placements for all patients receiving weekly cisplatin (Mitra et al., 2011).

Even as concerns to treatment interruptions depending on the CT schedule employed the data in the literature are contradictory. Three-weekly regimen was found to be associated with more delays (41\% vs $29 \%$ ) and omissions of CT $(17.4 \%$ vs $5.6 \%)$ resulting in lesser patients achieving cumulative doses beyond $200 \mathrm{mg} /$ $\mathrm{m} 2$, potentially lowering dose-intensity (Ho et al., 2008). The average dose intensity of weekly cisplatin $(26.5 \mathrm{mg} /$ $\mathrm{m} 2$ /week) has been reported to be equivalent to that of three-weekly regimen $\left(28.9 \mathrm{mg} / \mathrm{m}^{2} /\right.$ week) (Homma et al., 2011). Fayette et al. found higher incidence of secondary hospitalizations and RT interruptions ( $\geq 3$ days) with 3-weekly cisplatin; although with a significantly better OS with 3-weekly regimen (5 years OS: $62.3 \%$; $95 \%$ CI [51.6-71.3]) than with weekly cisplatin (5 years OS: $52.6 \%$; 95\% CI [44.5-66.0]) (Fayette et al., 2015). Several other institutional reports have described their results with weekly cisplatin at $40 \mathrm{mg} / \mathrm{m}^{2}$ (Beckmann et al., 2005; Steinmann et al., 2009) and $30 \mathrm{mg} / \mathrm{m}^{2}$ (Traynor et al., 2010). Overall, these results suggests comparable efficacy at $30-40 \mathrm{mg} / \mathrm{m}^{2}$, with a potentially more favourable acute systemic toxicity profile with weekly cisplatin. Despite these benefits with the weekly schedule, it is important to note that the most widely accepted standard of care, supported by level I evidence, remains the bolus cisplatin schedule.

Combined modality chemoradiation therapy has taken a 'central place' in the treatment of locally advanced squamous cell carcinoma of head and neck. The optimal scheduling of cisplatin with regard to efficacy and safety profile is very much in question. Unfortunately, till date no level I evidence exists to support the use of weekly cisplatin towards improving local control or survival with reduced toxicities. In this review, after scrutinizing the literature, we cannot assume that one treatment schedule is superior to the other. However, in view of toxicities associated with the standard three-weekly cisplatin based chemoradiation regime specially in developing countries like India, with limited resources and the cost of hospitalization for inpatient care for the management of acute toxicities, it's the right time to search for better alternative schedules substituting the "contemporary standard of care three-weekly concurrent cisplatin". Unfortunately, before replacing the standard three-weekly schedule there are still many questions to be answered suggesting a need to conduct head-to-head phase III randomized trial examining high-dose three-weekly versus weekly cisplatin schedule concurrent with radiation therapy in LA-HNC.

\section{References}

Adelstein DJ, Li Y, Adams GL, et al (2003). An intergroup phase III comparison of standard radiation therapy and two schedules of concurrent chemoradiotherapy in patients with unresectable squamous cell head and neck cancer. J Clin Oncol, 21, 92-8.

Al-Sarraf MD (2007). The role of concurrent chemo-radiotherapy in patients with head and neck cancers: a review. Gulf $J$ Oncol, 7, 8-16.

Asif R, Chandra K, Chopra V, Bhatt ML (2003). Concurrent cisplatin and radiotherapy in advanced head and neck cancer. Indian J Otolaryngol Head Neck Surg, 55, 94-6.

Bagri PK, Kapoor A, Kalwar A, et al (2014). Comparative analysis of cisplatin-induced nephrotoxicity in head and neck cancer and carcinoma cervix during concurrent chemoradiotherapy. South Asian J Cancer, 3, 217-20.

Bahl M, Siu LL, Pond GR, et al (2004). Tolerability of the Intergroup 0099 (INT 0099) regimen in locally advanced nasopharyngeal cancer with a focus on patients' nutritional status. Int J Radiat Oncol Biol Phys, 60, 1127-36.

Beckmann GK, Hoppe F, Pfreundner L, Flentje MP (2005). Hyperfractionated accelerated radiotherapy in combination with weekly cisplatin for locally advanced head and neck cancer. Head Neck, 27, 36-43.

Bernier J, Domenge C, Ozsahin M, et al (2004). Postoperative irradiation with or without concomitant chemotherapy for locally advanced head and neck cancer. $N$ Engl J Med, 350, 1945-52.

Bonner JA, Harari PM, Giralt J, et al (2006). Radiotherapy plus Cetuximab for squamous cell carcinoma of the head and neck. N Engl J Med, 354, 567-78.

Bourhis J, Lapeyre M, Tortochaux J, et al (2006). Phase III randomized trial of very accelerated radiation therapy compared with conventional radiation therapy in squamous cell head and neck cancer: a GORTEC trial. J Clin Oncol, 24, 2873-8.

Browman GP, Hodson DI, Mackenzie RG, Bestic N, Zuraw L (2001). Cancer care ontario practice guideline initiative head and neck cancer disease site group: choosing a concomitant chemotherapy and radiotherapy regimen for squamous cell head and neck cancer: a systematic review of the published literature with subgroup analysis. Head Neck, 23, 579-89.

Calais G, Alfonsi M, Bardet E, et al (1999). Randomized trial of radiation therapy versus concomitant chemotherapy and radiation therapy for advanced-stage oropharynx carcinoma. J Natl Cancer Inst, 91, 2081- 6. 


\section{Preety Negi et al}

Cooper JS, Pajak TF, Forastiere AA, et al (2004). Post-operative concurrent radiotherapy and chemotherapy for high-risk squamous cell carcinoma of the head and neck. $N$ Engl $J$ Med, 350, 1937-44.

De Jongh FE, Van Veen RN, Veltman SJ, et al (2003). Weekly high-dose cisplatin is a feasible treatment option: Analysis on prognostic factors for toxicity in 400 patients. Br J Cancer, 88, 1199-206.

Espeli V, Zucca E, Ghielmini M, et al (2012). Weekly and 3-weekly cisplatin concurrent with intensity-modulated radiotherapy in locally advanced head and neck squamous cell cancer. Oral Oncol, 48, 266-71.

Fayette J, Molin Y, Lavergne E, et al (2015). Radiotherapy potentiation with weekly cisplatin compared to standard every 3 weeks cisplatin chemotherapy for locoregionally advanced head and neck squamous cell carcinoma. Drug Des Devel Ther, 9, 6203-10.

Florea AM, Busselberg D (2011). Cisplatin as an anti-tumour drug: cellular mechanism of activity, drug resistance and induced side effects. Cancers, 3, 1351-71.

Geeta SN, Padmanabhan TK, Samuel J, Pavithran K, Iyer S, Kuriakose MA (2006). Comparison of acute toxicities of two chemotherapy schedules for head and neck cancers. $J$ Cancer Res Ther, 2, 100-4.

Geiger JL, Lazim AF, Walsh FJ, et al (2014). Adjuvant chemoradiation therapy with high-dose versus weekly cisplatin for resected, locally-advanced HPV/p16-positive and negative head and neck squamous cell carcinoma. Oral Oncol, 50, 311-8.

Gladkov OA, Vazhenin AV, Sharabura TM, et al (2007). Effectiveness of different regimens of combined treatment (cisplatin + radiotherapy) for intraoral and oropharyngeal cancer. Vopr Onkol, 53, 575-7.

Glaser MG, Leslie MD, O'Reilly SM, Cheesman AD, Newlands ES (1993). Weekly cisplatinum concomitant with radical RT in the treatment of advanced head and neck cancer. Clin Oncol, 5, 286-9.

Goncalves MS, Silveira AF, Teixeira AR, Hyppolito MA(2013). Mechanisms of cisplatin ototoxicity: theoretical review. $J$ Laryngol Otol, 127, 536-41.

Gupta T, Agarwal JP, Laskar SG, Parikh PM, Cruz AKD, Dinshaw KA (2009). Radical radiotherapy with concurrent weekly cisplatin in loco-regionally advanced squamous cell carcinoma of the head and neck: a single-institution experience. Head Neck Oncol, 1, 17.

Hao D, Ritter MA, Oliver T, Browman GP (2006). Platinumbased concurrent chemoradiotherapy for tumours of the head and neck and the esophagus. Semin Radiat Oncol, 16, 10-9.

Ho KF, Swindell R, Brammer CV (2008). Dose intensity comparison between weekly and 3-weekly cisplatin delivered concurrently with radical radiotherapy for head and neck cancer: a retrospective comparison from New cross hospital, Wolverhampton, UK. Acta Oncol, 47, 1513-8.

Homma A, Inamura N, Oridate N, et al (2011). Concomitant weekly cisplatin and radiotherapy for head and neck cancer. Jpn J Clin Oncol, 41, 980-6.

Huguenin P, Beer KT, Allal A (2004). Concomitant cisplatin significantly improves loco-regional control in advanced head and neck cancers treated with hyperfractionated RT. $J$ Clin Oncol, 22, 4665-73.

Jemal A, Bray F, Center MM, Ferlay J, Ward E, Forman D (2011). Global cancer statistics. Cancer J Clin, 61, 69-90.

Kang MH, Kang JH, Song HN, et al (2015). Concurrent chemoradiation with low-dose weekly cisplatin in locally advanced stage IV head and neck squamous cell carcinoma. Cancer Res Treat, 47, 441-7.

Kiyota N, Tahara M, Okano S, et al (2012). Phase II feasibility trial of adjuvant chemoradiotherapy with 3-weekly cisplatin for Japanese patients with post-operative high-risk squamous cell carcinoma of the head and neck. Jpn J Clin Oncol, 42, 927-33.

Kose F, Besen A, Sumbul T, et al (2011). Weekly cisplatin versus standard three-weekly cisplatin in concurrent chemoradiotherapy of head and neck cancer: the Baskent University Experience. Asian Pac J Cancer Prev, 12, 1185-8.

Krstevska V, Stojkovski I, Ivanovska BZ (2012). Concurrent radiochemotherapy in locally-regionally advanced oropharyngeal squamous cell carcinoma: analysis of treatment results and prognostic factors. Radiat Oncol, 7, 78.

Kulkarni MR (2013). Head and neck cancer burden in India. Int J Head Neck Surg, 4, 29-35.

Lawrence TS, Blackstock AW, McGinn C (2003). The mechanism of action of radiosensitization of conventional chemotherapeutic agents. Semin Radiat Oncol, 13, 13-21.

Maqbool LM, Malik TR, Afroza F, Khan NA, Haq M, Patigaroo AR (2012). Treatment outcome with weekly cisplatin concurrent with radiation therapy in locally advanced head and neck squamous cell carcinoma. JIMSA, 25.

Mitra D, Choudhury K, Rashid MA (2011). Concurrent chemotherapy in advanced head and neck carcinoma - A prospective randomized trial. Bangladesh J Otorhinolaryngol, 17, 88-95.

Mohanty BK, Bahadur S, Lal P, Gairola M, Rath GK (2000). Textbook of Radiation Oncology: Principles and Practice, Eds Rath GK and Mohanty BK. BI Churchill Livingstone, New Delhi, 131-99.

Newlin HE, Amdur RJ, Riggs CE, Morris CG, Kirwan JM, Mendenhall WM (2010). Concomitant weekly cisplatin and altered fractionation radiotherapy in locally advanced head and neck cancer. Cancer, 116, 4533-40.

Osman N, Elamin YY, Rafee S, et al (2014). Weekly cisplatin concurrently with radiotherapy in head and neck squamous cell cancer: a retrospective analysis of a tertiary institute experience. Eur Arch Otorhinolaryngol, 271, 2253-9.

Pajak TF, Laramore GE, Marcial VA, et al (1991). Elapsed treatment days - a critical item for radiotherapy quality control review in head and neck trials: RTOG report. Int $J$ Radiat Oncol Biol Phys, 20, 13-20.

Pala M, Odrazka K, Holeckova P, et al (2012). Definitive radiochemotherapy with weekly cisplatin in patients with head and neck cancer; single institution outcome analysis. J Buon, 17, 471-7.

Pignon JP, Bourhis J, Domenge C, Designe L (2000). Chemotherapy added to locoregional treatment for head and neck squamous cell carcinoma: three meta-analyses of updated individual patient data. MACH-NC Collaborative Group Meta-analysis of chemotherapy on head and neck cancer. Lancet, 355, 949-55.

Pignon JP, Maitre LA, Bourhis J (2007). Meta-Analyses of Chemotherapy in Head and Neck Cancer (MACH-NC): an update. Int J Radiat Oncol Biol Phys, 69,112-4.

Pignon JP, le Maitre A, Maillard E, Bourhis J (2009). Metaanalysis of chemotherapy in head and neck cancer (MACH$\mathrm{NC})$ : an update on 93 randomized trials and 17,346 patients. Radiother Oncol, 92, 4-14.

Quon H, Leong T, Haselow R, Leipzig B, Cooper J, Forastiere A (2011). Phase III study of radiation therapy with or without cis-platinum in patients with unresectable squamous or undifferentiated carcinoma of the head and neck: an intergroup trial of the eastern cooperative oncology group (E2382). Int J Radiat Oncol Biol Phys, 8, 719-25.

Rademaker-Lakhai JM, Crul M, Zuur L, et al (2006). Relationship between cisplatin administration and the development of ototoxicity. J Clin Oncol, 24, 918-24. 
Rutten H, Pop LA, Janssens GO, et al (2011). Long-term outcome and morbidity after treatment with accelerated radiotherapy and weekly cisplatin for locally advanced head and neck cancer: Results of a multidisciplinary late morbidity clinic. Int J Radiat Oncol Biol Phys, 81, 923-9.

Rosenberg B, Vancamp L, Krigas T (1965). Inhibition of cell division in Escherichia coli by electrolysis products from a platinum electrode. Nature, 205, 698-9.

Sambargi UC, Mahesh DR, Pai A, Maligi P, Ramanarayan BK, Sanjay CJ (2012). Recent advances in chemotherapy for head and neck cancers. J Orofac Sci, 4, 15-9.

Steinmann D, Cerny B, Karstens JH, Bremer M (2009). Chemoradiotherapy with weekly cisplatin $40 \mathrm{mg} / \mathrm{m}^{2}$ in 103 head and neck cancer patients: a cumulative dose-effect analysis. Strahlenther Onkol, 185, 682-8.

Traynor AM, Richards GM, Hartig GK, et al (2010). Comprehensive IMRT plus weekly cisplatin for advanced head and neck cancer: The University of Wisconsin Experience. Head Neck, 32, 599-606.

Tsan DL, Lin CY, Kang CJ, et al (2012). The comparison between weekly and three-weekly cisplatin delivered concurrently with radiotherapy for patients with postoperative high-risk squamous cell carcinoma of the oral cavity. Radiat Oncol, 7, 215.

Uygun K, Bilici A, Karagol H, et al (2009). The comparison of weekly and three-weekly cisplatin chemotherapy concurrent with radiotherapy in patients with previously untreated inoperable non-metastatic squamous cell carcinoma of the head and neck. Cancer Chemother Pharmacol, 64, 601-5.

Wee J, Tan EH, Tai BC (2005). Randomized trial of radiotherapy versus concurrent chemoradiotherapy followed by adjuvant chemotherapy in patients with american joint committee on cancer / international union against cancer stage III and IV nasopharyngeal cancer of the endemic variety. J Clin Oncol, 23, 6730-8.

Wendt TG, Grabenbauer GG, Rodel CM, et al (1998). Simultaneous radiochemotherapy versus radiotherapy alone in advanced head and neck cancer: a randomized multicentre study. J Clin Oncol, 16, 1318-24.

Yang LX, Douple EB, Wang HJ (1995). Irradiation enhances cellular uptake of carboplatin. Int J Radiat Oncol Biol Phys, 33, 641-6.

Zenda S, Onozawa Y, Tahara M, et al (2007). Feasibility study of single agent cisplatin and concurrent radiotherapy in Japanese patients with squamous cell carcinoma of the head and neck: preliminary results. Jpn J Clin Oncol, 37, 725-9. 